An investigation of neighborhood-level social, economic and physical factors for railway suicide in

\title{
Victoria, Australia
}

Lay San Too ${ }^{a,}{ }^{,}$, Matthew J. Spittal ${ }^{b}$, Lyndal Bugeja ${ }^{a}$, Allison Milner ${ }^{c}$, Mark Stevenson ${ }^{a}$, Roderick McClure $^{d}$

${ }^{a}$ Monash Injury Research Institute, Monash University, Victoria, Australia

${ }^{b}$ Centre for Mental Health, Melbourne School of Population and Global Health, The University of Melbourne, Victoria, Australia

${ }^{c}$ Centre for Health Equity, Melbourne School of Population and Global Health, The University of Melbourne, Victoria, Australia

${ }^{d}$ Harvard Injury Control Research Center, Harvard School of Public Health, Boston, Massachusetts, USA 


\section{Abstract}

Background: This study investigates the associations between railway suicide and neighborhood social, economic, and physical determinants using postcode-level data. It also examines whether the associations are influenced by having high concentration of high-risk individuals in a neighborhood area.

Methods: Railway suicide cases from Victoria, Australia for the period of 2001-2012, their age, sex, year of death, usual residential address and suicide location were obtained from the National Coronial Information System. Univariate negative binomial regression models were used to estimate the association between railway suicide and neighborhood-level social, economic and physical factors. Variables which were significant in these univariate models were then assessed in a multivariate model, controlling for age and sex of the deceased and other known confounders.

Results: Findings from the multivariate analysis indicates that an elevated rate of railway suicide was strongly associated with neighborhood exposure of higher number of railway stations (IRR $=1.30$ $95 \% \mathrm{Cl}=1.16-1.46)$. Other significant neighborhood risk factors included patronage volume (IRR = $1.06,95 \% \mathrm{Cl}=1.02-1.11)$ and train frequency $(\mathrm{IRR}=1.02,95 \% \mathrm{Cl}=1.01-1.04)$. An increased number of video surveillance systems at railway stations and carparks was significantly associated with a modest reduction in railway suicide risk (IRR $=0.93,95 \% \mathrm{Cl}=0.88-0.98)$. These associations were independent of concentration of high-risk individuals.

Limitations: Railway suicide may be under-reported in Australia.

Conclusions: Interventions to prevent railway suicide should target vulnerable individuals residing in areas characterised by high station density, patronage volume and train frequency. 
Keywords: Suicide; railway; neighborhood; socio-environment 


\section{Introduction}

Railway suicide causes far-reaching and serious implications. It not only has considerable impacts for the victims including death and serious physical disability, but also has traumatising effects on family and friends as well as witnesses to the suicide incident (e.g., train drivers, railway staff and passengers) (Lukaschek et al., 2011; Odonnell et al., 1994). Other significant consequences include financial loss through service delays and driver absenteeism (Lukaschek et al., 2011; Silla et al., 2012). Railway suicide may also trigger imitative behaviour (i.e. high-risk individuals using the same suicide method following exposure to an incident) (Sonneck et al., 1994).

Railway suicide is highly lethal, with up to $94 \%$ of attempts being fatal (Krysinska and De Leo, 2008). Consistent with studies from other countries (Gershon et al., 2008; Rådbo et al., 2005), a report from Victoria shows that the majority of rail related fatalities are suicides (Wigglesworth et al., 2005). In Australia, railway suicide represented 3.3\% of all suicides in 2011, with the highest rate reported in Victoria (6.6\%) (Australian Bureau of Statistics, 2013). Consistent with studies from other countries (Gershon et al., 2008; Rådbo et al., 2005), a report from Victoria shows that the majority of rail-related fatalities are suicides (Wigglesworth et al., 2005).

Previous research on railway suicide has largely focused on its descriptive epidemiology and the identification of individual risk factors (Krysinska and De Leo, 2008; Mishara, 2007; Ratnayake et al., 2007; van Houwelingen and Kerkhof, 2008) and relatively few studies have explored socioenvironmental factors (Too et al., 2014). There is strong evidence for the ecological relationship between socio-environments and suicide. For example, area-level socioeconomic deprivation including high unemployment and divorce are associated with an increased population risk of suicide (Barth et al., 2011; Rehkopf and Buka, 2006; Taylor et al., 2005). Social fragmentation (i.e. poor community connection) has also been reported as a strong indicator for suicide (Congdon, 2013; Mok et al., 2013). Other socio-environmental predictors include neighborhood violence, alcohol 
outlet density and the availability of mental health services (Branas et al., 2011; Giotakos et al., 2012; Kennedy et al., 1999). Understanding the impact of the socio-environment on railway suicide is essential as such knowledge is useful to characterise and identify high-risk areas for targeted interventions to prevent railway suicide.

The current study aimed to investigate the ecological associations between railway suicide and a range of neighborhood social, economic and physical determinants. The determinants included social fragmentation, socioeconomic deprivation, train-related factors, and some other socio-environmental factors that have been shown to be linked with suicide. It is possible that individuals at risk of suicide are attracted to reside in an area with particular characteristics (e.g., closer to mental health services or the anonymity of the location). For this reason, this study also sought to determine whether the associations were a product of contextual effects (i.e. the impacts of area characteristics on individuals) or compositional effects (i.e. the concentration of high-risk individuals).

\section{Methods}

\subsection{Study design}

This retrospective study used an ecological design, based on postcode-level data from Victoria, Australia. Postcodes are the smallest geographical units for which reliable data were available for all the variables used in this study. The use of this small geographic unit was advantageous as a previous meta-analysis has shown that smaller geographical units (i.e. environment closer to peoples' homes) have stronger impacts on individuals compared with larger geographical units (Meijer et al., 2012).

\subsection{Suicide counts}

Railway suicide data were obtained from the National Coronial Information System (NCIS). The NCIS is a national internet-based data storage and retrieval system for all deaths investigated by 
Australian coroners. Data is available for Victoria from 1 July 2000 onwards. It contains coded and free text demographic information such as age, sex, and usual residential address_i.e. the location where the individual usually resided at around the time of suicide and this is also referred as home address), as well as four full text reports generated for each investigation: the summary of circumstances from the Police Report of Death to the Coroner form, autopsy report, toxicology report, and report of coroner's finding. The NCIS offers the best available information on suicide mortality and is regarded as an unbiased source of suicide figures in Australia (Driscoll et al., 2003). Because the suicide data for the most recent years are usually not available in NCIS due to the time required for coronial investigations (De Leo et al., 2010), this study included the period of 2001-2012 for which reliable data are available.

Cases classified as an intentional self-harm by rail vehicle from Victoria, Australia between 1 January 2001 and 31 December 2012 were extracted and reviewed to ensure they were railway suicide cases. These cases were then cross-referenced with railway suicide deaths identified by the Coroners Court of Victoria. Cases were excluded if they: (1) were still under investigation at 31 October 2014 (when the data were extracted for analysis); (2) had an unknown place of usual residence; (3) had a postcode of usual residence located outside Victoria; or (4) died after being hit by a tram. For cases included, data on age, sex, year of death, usual residential address and suicide location were extracted for each case and used in the analysis.

\subsection{Population data}

Population estimates for Victorian postcodes were retrieved from the ABS Census, which is conducted every five years (i.e. 2001, 2006 \& 2011). Population data based on the 2001 Census were used for railway suicide cases from 2001 to 2003, population data based on the 2006 Census were used for cases from 2004 to 2008, and population data based on the 2011 Census were used for cases from 2009 to 2012. 
Residential postcodes of railway suicide cases were merged with a range of neighborhoodlevel variables, which comprise social, economic and physical data. These data were matched with the year of the suicidal event as closely as possible. In particular, access to data related to the railway network was coordinated by the Department of Transport, Planning \& Local Infrastructure (State Government Victoria). This data was provided by several key Victorian railway regulators and operators, including Public Transport Victoria, Victrack, Metro trains, and V/Line. Table 1 shows the details of all neighborhood-level variables included in the analysis.

\subsection{Statistical analysis}

Descriptive analysis was performed to report details of suicide location and its distance from the deceased's home. The distances were estimated using Google Maps application. Because our data displayed evidence of over-dispersion, negative binomial regression models were used to estimate the ecological associations between railway suicide and neighborhood-level social, economic and physical factors, with an offset term for the population size in each postcode. We used robust standard errors (based on postcode) to account for a possible within-postcode correlation in the outcome. All coefficients were exponentiated to interpret these results as incidence rate ratios (IRRs).

Univariate models were first used to assess all variables individually. Variables which were significant in the univariate models were then carried forward and tested in a multivariate model after controlling for the effects of age and sex of the deceased (and their interaction) and other known confounder(s). Compositional effects were also measured in the multivariate model by adding factors related to concentration of individuals at increased risk for suicide (e.g., males and persons aged 15-44 years) (Australian Bureau of Statistics, 2014). All analyses were conducted using Stata SE 13.1 (Stata Corp., College Station, Texas). 


\subsection{Ethical approval}

The study was approved by the Monash University Human Research Ethics Committee and the Justice Human Research Ethics Committee (State Government Victoria).

\section{Results}

\subsection{Descriptive results}

During 2001-12, 334 railway suicides occurred in Victoria were included in the study. This accounted for $70.5 \%$ of all rail-related deaths, which was far more frequent than deaths classified as unintentional $(23.8 \%)$, undetermined intent $(3.4 \%)$, unlikely to be known $(2.1 \%)$, and assault $(0.2 \%)$. Over ninety percent of the suicides were found in an urban area and the remaining located in a regional area. The majority of railway suicides $(67.4 \%)$ took place on the open track (i.e. anywhere between a station and a road/pedestrian level crossing), with the remainder within the station itself (16.5\%), at level crossings (i.e. where the road crosses train tracks) $(10.8 \%)$ and at pedestrian crossings (5.4\%). Approximate seventy percent of the suicide location was within five kilometres (less than 1 hour's walk) from the deceased's home. Of these, most cases had a distance being no more than two and half kilometres (less than 30 minutes' walk).

Table 2 shows the results of an interaction between the deceased's sex and age and the number of deaths. Compared with females aged 14-34 years (the reference category), males in the same age group had three times higher risk of railway suicide. These males also had the highest risk compared with other groups whereas the lowest risk was among those females aged 60 years and over.

\subsection{Findings from the univariate analyses}

Table 3 presents the results of univariate analyses for the risk of railway suicide during the study period. The analyses show a significant association between an increased risk of railway suicide and higher level of social fragmentation in a neighborhood area (IRR $=1.08,95 \% \mathrm{Cl}=1.04$ - 
1.12). In particular, among the neighborhood indicators used to compute social fragmentation score, a higher proportion of lone persons (IRR $=1.05,95 \% \mathrm{Cl}=1.02-1.07)$, persons in rented accommodation $(\mathrm{IRR}=1.01,95 \% \mathrm{Cl}=1.00-1.02)$, and unmarried persons $(\mathrm{IRR}=1.07,95 \% \mathrm{Cl}=1.05$ 1.09) were a significant risk factor for railway suicide.

Greater socioeconomic advantaged (i.e. Index of Relative Socio-economic Advantage and Disadvantage, Index of Economic Resources) was positively associated with an elevated rate of railway suicide, but this relationship was not significant. Of the key socioeconomic measures included in the indexes, a significant association between higher proportion of unemployment and higher risk of railway suicide was observed (IRR $=1.05,95 \% \mathrm{Cl}=1.01-1.09)$. Higher level of school completion was significantly associated with an increased risk of railway suicide $(\mathrm{IRR}=0.99,95 \% \mathrm{Cl}=$ 0.98-0.99).

In terms of neighborhood physical exposures, presence of railway tracks (IRR $=2.11,95 \% \mathrm{Cl}$ $=1.50-2.97)$, high train frequency $(I R R=1.04,95 \% \mathrm{Cl}=1.03-1.05)$, high number of stations $(I R R=$ $1.38,95 \% \mathrm{Cl}=1.26-1.52)$, and high proportion of people travel to work by train $(\mathrm{IRR}=1.03,95 \% \mathrm{Cl}=$ 1.02-1.04) were significantly associated with greater risk of railway suicide. Other positive but less significant indicators include train speed (IRR $=1.00,95 \% \mathrm{Cl}=1.00-1.01)$, number of surveillance units $(\mathrm{IRR}=1.04,95 \% \mathrm{Cl}=1.01-1.07)$, and volume of station patronage $(\mathrm{IRR}=1.04,95 \% \mathrm{Cl}=1.02-$ 1.07). Higher density of alcohol outlets was also found to be significantly associated with higher risk of railway suicide $(\mathrm{IRR}=1.01,95 \% \mathrm{Cl}=1.00-1.02)$.

Both of the indicators representing concentration of high-risk individuals were significant in the analyses. Railway suicide risk was negatively associated with the proportion of males (IRR $=0.87$, $95 \% \mathrm{Cl}=0.79-0.95)$ but positively associated with the proportion of people aged between 15 and 44 years $(\operatorname{IRR}=1.02,95 \% \mathrm{Cl}=1.01-1.04)$. The negative association between male proportion and railway suicide risk was possibly resulted from the low rate of railway suicide in areas with maledominant industries such as agriculture and defence force. 


\subsection{Findings from the multivariate analysis}

Table 4 summarises the outcomes of multivariate analysis for railway suicide risk. In the multivariate model, we adjusted for the effects of age and sex of the deceased and included several significant factors from the univariate models (we excluded weakly associated factors to give sufficient power for the analysis given the relatively small number of railway suicides). Considering socioeconomic status is usually associated with the number of railway stations in a local area, the relevant measure of socioeconomic deprivation (i.e. Index of Economic Resources) was also placed in the model to control for possible confounding effect. As a result, we found that socioeconomic deprivation remained non-significant while the number of stations remained significant $(I R R=1.33$, $95 \% \mathrm{Cl}=1.18-1.49)$ in the multivariate model.

Other physical exposures such as higher volume of station patronage $(\mathrm{IRR}=1.05,95 \% \mathrm{Cl}=$ 1.01-1.10) and higher train frequency (IRR $=1.02,95 \% \mathrm{Cl}=1.01-1.04)$ were significantly associated with an increased risk of railway suicide. The positive association between the number of video surveillance systems (at stations and carparks) and railway suicide in the univariate model became negative in the multivariate model (IRR $=0.93,95 \% \mathrm{Cl}=0.88-0.98)$. This was likely explained by the close correlation between the number of video surveillance systems and station density.

A significant positive association was found between social fragmentation and railway suicide when assessing only the effects of age, sex, social fragmentation and socioeconomic deprivation in the model $(\mathrm{IRR}=1.09,95 \% \mathrm{Cl}=1.05-1.14)$. However, the significant association became non-significant after controlling for several physical indicators as shown in the Table 4.

Overall, railway suicide risk was significantly influenced by the neighborhood context after adjusting for the concentration of high-risk individuals. Proportions of males and persons aged between 15 and 44 years changed from significant in the univariate models to non-significant in the multivariate model. This suggests that local surroundings had stronger effects on the risk of railway suicide than the concentration of high-risk individuals. 


\section{Discussion}

\subsection{Main findings and interpretations}

We investigated the associations between railway suicide and neighborhood social, economic and physical factors in a Victoria for the period of 2001-2012, and the influence of concentration of high-risk individuals on the associations. Our findings indicated that majority of railway suicides occurred within an urban area and on the open track. This is consistent with the studies conducted in Sweden, and Queensland, Australia, which found that railway suicide deaths were mostly located on the railway track in between a station and a level crossing (De Leo and Krysinska, 2008; Rådbo et al., 2005). We also found that railway suicide victims were more likely to die near to where they lived, with a distance being less than five kilometres. Comparable findings were reported in England and Canada. The England study showed that most railway suicide incidents took place within four or five kilometres from the deceased's residence (Abbot et al., 2003) and the Canadian study reported that approximate three-quarter of victims selected the station closest to their home (Mishara, 1999).

During 2001-2012 in Victoria, males aged 14-34 years had the highest risk of railway suicide among all groups. Particularly, they had a three times higher risk compared with females in the same age group. A review described a similar result, where males were found to have greater risk of railway suicide than females (Krysinska and De Leo, 2008). It also concluded that railway suicide victims are usually young people aged between 20 and 40 years (Krysinska and De Leo, 2008).

A study in England and Wales showed that high level of social fragmentation was associated with high suicide mortality independent of socioeconomic deprivation (Middleton et al., 2004). Another study reported that social fragmentation was a stronger indicator for female suicide whereas deprivation was a stronger indicator for male suicide (Congdon, 2013). However, based on our analyses, railway suicide was more strongly associated with social fragmentation than deprivation, but this finding was not significant after adjusting for the effects of train-related factors. 
Several train-related indicators were shown to influence railway suicide risk. In the multivariate model, station density was the factor with the strongest effect. This supports the finding in Vienna, where positive association between the number of station and railway suicide was reported (Niederkrotenthaler et al., 2012). The current findings also strengthens the evidence for the relationships of an elevated rate of railway suicide with higher train frequency and higher passenger volume (Too et al., 2014). However, contrary to the previous results (Niederkrotenthaler et al., 2012), our adjusted model showed that an increased number of video surveillance systems at stations and carparks was associated with a reduced risk of railway suicide.

A number of studies have shown that the availability of the suicide method is an important risk factor for suicide (Florentine and Crane, 2010; Sarchiapone et al., 2011; Yip et al., 2012). For instance, Thomas and his colleagues found that suicide rates in England and Wales increased by $20 \%$ after domestic coal gas became widely available during 1919-1935 (Thomas et al., 2011). They also reported that availability of barbecue charcoal gas was associated with a $64 \%$ rise of suicide rates between 1999 and 2006 in Taiwan. Our findings confirm that train-related indicators (i.e. higher number of station, higher train frequency, and higher passenger number) were strongly associated with railway suicide. Their impacts were stronger compared to social and economic exposures.

Importantly, we found that railway suicide risk was determined by neighborhood context independent of concentration of high-risk individuals. It was that area characteristics themselves but not high proportion of high-risk people in an area influenced the risk of railway suicide. This is contrary to the finding from a Danish study, which found that suicide risk was primarily influenced by the characteristics of residents and limitedly affected by the local environments (Agerbo et al., 2007). Altogether, our study suggests the significance of local surroundings to the victims of railway suicide. Interventions should target vulnerable individuals residing in areas characterised by high station density, patronage volume and train frequency to reduce railway suicide in Victoria.

\subsection{Strengths and limitations}


To our knowledge, this is the first study investigating a variety of neighborhood social, economic and physical factors associated with railway suicide at the population level. It considers both the contextual and compositional effects on the risk of railway suicide. Our study provides the foundation for a larger body of work on railway suicide using more comprehensive measures than previously available.

Nevertheless, our study has several limitations. Railway suicide data may be under-reported due to coronial delays and misclassification of suicides as other causes of death such as undetermined intent or unintentional (Australian Bureau of Statistics, 2007; World Health Organization, 2014). Most of the neighborhood-level data are not available for the whole study period. For instance, all social and economic data have to be based on the Census which is only available in 2001, 2006 and 2011. By using data from the Census year most closely to the year of death, we assume that these data stay constant across non-Census years. However, we believe that this assumption is unlikely to have prominently impacted on our findings. Another limitation includes using proxy measures for familiarity with trains (e.g., number of station patronage). As such, higher patronage volume does not imply that railway suicide victims were familiar with trains. Further, we found that 27 cases $(8.1 \%)$ were an inpatient at a psychiatric hospital at the time of suicide. Most of them were on leave or absconded prior to suicide and very few left hospital unnoticed or unescorted, based on available information. Among inpatient cases, there athere are fivea few cases have their temporary residence (e.g., psychiatric hospital (temporary residence) \& rehabilitation center)-recorded as usual residence. For these cases, it is likely that the social and economic contexts of temporary residence have little impact on their risk of railway suicide-and the associations between train-related factors and railway suicide would have been slightly strengthened given that psychiatric hospitals are usually located in the vicinity of the railways in Victoria.

\section{Conclusions}


Our findings suggest interventions to reduce railway suicides should target vulnerable people (e.g., individuals with affective and psychotic disorders (van Houwelingen and Kerkhof, 2008)) residing in areas that are characterised by high station density, patronage volume and train frequency. Relevant interventions for which there is some evidence of effectiveness include increasing surveillance or installing fencing along railway tracks within high-risk neighborhoods (Cox et al., 2013). We would encourage healthcare professionals, police officers and other gatekeepers who work in these areas to be aware of a heightened risk for railway suicide in vulnerable people they are dealing with. We walso encourage international scholars, public health professionals, policy makers and railway system owners/operators to undertake similar investigations to further refine knowledge about environmental risks for railway suicide and to undertake trials of environmental solutions in targeted settings. 


\section{References}

Abbot, R., Young, S., Grant, G., Goward, P., Seager, P., \& Ludlow, J., 2003. Railway suicide: an investigation of individual and organizational consequences. Doncaster: Doncaster and South Humber Healthcare NHS Trust.

Agerbo, E., Sterne, J. A. C., \& Gunnell, D. J., 2007. Combining individual and ecological data to determine compositional and contextual socio-economic risk factors for suicide. Soc. Sci. Med. 64, 451-461.

Australian Bureau of Statistics, 2007. Information Paper: External Causes of Death, Data Quality, 2005. Cat. no. 3317.0.55.001. Canberra: Australian Bureau of Statistics.

Australian Bureau of Statistics, 2013. 3303.0 - Causes of Death, Australia, 2011. Australia

Australian Bureau of Statistics, 2014. 3303.0 - Causes of Death, Australia, 2012 Australia: Australian Bureau of Statistics.

Barth, A., Sogner, L., Gnambs, T., Kundi, M., Reiner, A., \& Winker, R., 2011. Socioeconomic factors and suicide: an analysis of 18 industrialized countries for the years 1983 through 2007. J. Occup. Environ. Med. 53, 313-317.

Branas, C. C., Richmond, T. S., Ten Have, T. R., \& Wiebe, D. J., 2011. Acute Alcohol Consumption, Alcohol Outlets, and Gun Suicide. Subst. Use. Misuse. 46, 1592-1603.

Congdon, P., 2013. Assessing the impact of socioeconomic variables on small area variations in suicide outcomes in England. Int. J. Environ. Res. Public Health 10, 158-177.

Cox, G. R., Owens, C., Robinson, J., Nicholas, A., Lockley, A., Williamson, M., Cheung, Y. T. D., \& Pirkis, J., 2013. Interventions to reduce suicides at suicide hotspots: a systematic review. BMC Public Health, 13, 214. 
De Leo, D., Dudley, M. J., Aebersold, C. J., Mendoza, J. A., Barnes, M. A., Harrison, J. E., \& Ranson, D. L., 2010. Achieving standardised reporting of suicide in Australia: rationale and program for change. Med. J. Aust. 192, 452-456.

De Leo, D., \& Krysinska, K., 2008. Suicidal behaviour by train collision in Queensland, 1990-2004. Aust. N. Z. J. Psychiatry 42, 772-779.

Driscoll, T., Henley, G., \& Harrison, J., 2003. The National Coroners Information System as an information tool for injury surveillance. Catalogue no. INJCAT 60. Canberra: Australian Institute of Health and Welfare.

Florentine, J. B., \& Crane, C., 2010. Suicide prevention by limiting access to methods: a review of theory and practice. Soc. Sci. Med. 70, 1626-1632.

Gershon, R. R. M., Pearson, J. M., Nandi, V., Vlahov, D., Bucciarelli-Prann, A., Tracy, M., Tardiff, K., \& Galea, S., 2008. Epidemiology of subway-related fatalities in New York City, 1990-2003. Journal of Safety Research, 39, 583-588.

Giotakos, O., Tsouvelas, G., \& Kontaxakis, V., 2012. Suicide rates and mental health services in Greece. Psychiatriki, 23, 29-38.

Kennedy, H. G., Iveson, R. C., \& Hill, O., 1999. Violence, homicide and suicide: strong correlation and wide variation across districts. The British Journal of Psychiatry, 175, 462-466.

Krysinska, K., \& De Leo, D., 2008. Suicide on railway networks: Epidemiology, risk factors and prevention. Australian and New Zealand Journal of Psychiatry, 42, 763-771.

Lukaschek, K., Baumert, J., \& Ladwig, K. H., 2011. Behaviour patterns preceding a railway suicide: Explorative study of German Federal Police officers' experiences. BMC Public Health, 11.

Meijer, M., Röhl, J., Bloomfield, K., \& Grittner, U., 2012. Do neighborhoods affect individual mortality? A systematic review and meta-analysis of multilevel studies. Soc. Sci. Med. 74, 1204-1212. 
Middleton, N., Whitley, E., Frankel, S., Dorling, D., Sterne, J., \& Gunnell, D., 2004. Suicide risk in small areas in England and Wales, 1991-1993. Soc. Psychiatry Psychiatr. Epidemiol., 39, 45-52.

Mishara, B. L., 1999. Suicide in the Montreal subway system: Characteristics of the victims, antecedents, and implications for prevention. Can. J. Psychiatry 44, 690-696.

Mishara, B. L., 2007. Railway and metro suicides: Understanding the problem and prevention potential. Crisis 28, 36-43.

Mok, P. L., Leyland, A. H., Kapur, N., Windfuhr, K., Appleby, L., Platt, S., \& Webb, R. T., 2013. Why does Scotland have a higher suicide rate than England? An area-level investigation of health and social factors. J. Epidemiol. Community Health 67, 63-70.

Niederkrotenthaler, T., Sonneck, G., Dervic, K., Nader, I. W., Voracek, M., Kapusta, N. D., Etzersdorfer, E., Mittendorfer-Rutz, E., \& Dorner, T., 2012. Predictors of suicide and suicide attempt in subway stations: A population-based ecological study. J. Urban Health 89, 339-353.

Odonnell, I., Farmer, R., \& Tranah, T., 1994. Suicide on railways - Introduction. Soc. Sci. Med. 38, 399400.

Rådbo, H., Svedung, I., \& Andersson, R., 2005. Suicides and other fatalities from train-person collisions on Swedish railroads: A descriptive epidemiologic analysis as a basis for systemsoriented prevention. J. Safety Res. 36, 423-428.

Ratnayake, R., Links, P. S., \& Eynan, R., 2007. Suicidal behaviour on subway systems: A review of the epidemiology. J. Urban Health 84, 766-781.

Rehkopf, D. H., \& Buka, S. L., 2006. The association between suicide and the socio-economic characteristics of geographical areas: a systematic review. Psychol. Med. 36, 145-157.

Sarchiapone, M., Mandelli, L., losue, M., Andrisano, C., \& Roy, A., 2011. Controlling access to suicide means. Int. J. Environ. Res. Public Health 8, 4550-4562. 
Silla, A., Kallberg, V.-P., Rådbo, H., Whalley, S., \& Ryan, B., 2012. Summary and conclusion of D1.1 "Data concerning railway suicides and trespassing accidents". Finland: Teknologian Tutkimuskeskus VTT.

Sonneck, G., Etzersdorfer, E., \& Nagel-Kuess, S., 1994. Imitative suicide on the Viennese subway. Soc. Sci. Med. 38, 453-457.

Taylor, R., Page, A., Morrell, S., Harrison, J., \& Carter, G., 2005. Mental health and socio-economic variations in Australian suicide. Soc. Sci. Med. 61, 1551-1559.

Thomas, K., Chang, S. S., \& Gunnell, D., 2011. Suicide epidemics: the impact of newly emerging methods on overall suicide rates-a time trends study. BMC Public Health, 11, 314.

Too, L. S., Milner, A., Bugeja, L., \& McClure, R., 2014. The socio-environmental determinants of railway suicide: a systematic review. BMC Public Health 14, 1-10.

van Houwelingen, C. A. J., \& Kerkhof, A. J. F. M., 2008. Mental healthcare status and psychiatric diagnoses of train suicides. J. Affect. Disord. 107, 281-284.

Wigglesworth, E., Graham, A., \& Routley, V., 2005. Rail-related fatalities in Victoria, Australia: 19902002. Road Transp. Res. 14, 30-37.

World Health Organization, 2014. Preventing suicide: A global imperative. Geneva, Switzerland: World Health Organization.

Yip, P. S. F., Caine, E., Yousuf, S., Chang, S.-S., Wu, K. C.-C., \& Chen, Y.-Y., 2012. Means restriction for suicide prevention. Lancet 379, 2393-2399. 


\section{University Library}

\section{- M M N E R VA A gateway to Melbourne's research publications}

Minerva Access is the Institutional Repository of The University of Melbourne

Author/s:

Too, LS;Spittal, MJ;Bugeja, L;Milner, A;Stevenson, M;McClure, R

Title:

An investigation of neighborhood-level social, economic and physical factors for railway suicide in Victoria, Australia

Date:

2015-09-01

Citation:

Too, L. S., Spittal, M. J., Bugeja, L., Milner, A., Stevenson, M. \& McClure, R. (2015). An investigation of neighborhood-level social, economic and physical factors for railway suicide in Victoria, Australia. JOURNAL OF AFFECTIVE DISORDERS, 183, pp.142-148. https:// doi.org/10.1016/j.jad.2015.05.006.

Persistent Link:

http://hdl.handle.net/11343/59171 